\title{
ДОСЛІДЖЕННЯ ЗАКОНОМІРНОСТЕЙ РОЗПОВСЮДЖЕННЯ ВИКИДІВ ПРОДУКТІВ ЗГОРАННЯ В АТМОСФЕРУ ПІД ЧАС РОБОТИ КОМПРЕСОРНИХ СТАНЦІЙ
}

Розглянуто основні забруднювальні речовини та їхній склад, що найчастіше викидаються в атмосферу під час експлуатації компресорних станцій магістральних газопроводів. Найбілышу небезпеку створюють джерела забруднення атмосфери, пов'язані насамперед із процесами спалювання неорганічного палива. Встановлено, що в камерах згорання газоперекачувальних агрегатів газотурбінних двигунів утворюються оксид і діоксид азоту, оксид вуглецю та інші речовини, які забруднюють атмосферне повітря. Проведено аналіз поширення викидів забруднювальних речовин в атмосферному повітрі. Запропоновано схему траєкторії розповсюдження викидів продуктів згорання в атмосфері. Розроблено математичні залежності забруднення приземного шару атмосферного повітря викидами димових газів від джерел технологічного обладнання під час роботи компресорних станцій. Встановлено закономірності розповсюдження викидів у приземному шарі атмосфери. Запропоновано розрахункові залежності, які дають змогу оцінити зміну дальності розповсюдження шкідливих речовин залежно від швидкості викидних газів, висоти димової труби, напрямку і швидкості вітру та інших параметрів. Охарактеризовано закономірності відстані, на яку поширюються продукти згорання, яка пропорційна швидкості вітру і функціонально пов'язана з масою та швидкістю викидів продуктів згорання, висотою викидної труби, коефіцієнтами опору середовища.

Ключові слова: компресорна станція; навколишнє середовище; продукти згорання природного газу; атмосферне повітря.

Вступ. Газотранспортна система України є однією 3 найбільших за розмірами в Свропі, яка складається з газопроводів загальною довжиною майже 37 тис. км, 74 компресорних станцій з 713 газоперекачувальними агрегатами (ГПА), зокрема 438 з газотурбінним приводом і 96 газомотокомпресорів, енергоносієм для яких $є$ транспортований газ. На привід газоперекачувальних агрегатів витрачається 0,5-1,5\% природного газу від обсягу перекачування. Спалювання такої кількості газу погіршує рівень екологічної безпеки атмосфери в районах розташування компресорних станцій (Mikaelian, 2011; Horbiichuk \& Shchupak, 2011; Khalatov, Kostenko \& Parafiinyk, 2010; Hovdiak, \& Shymko, 2012), aдже атмосфера - це повітря, яким дихаємо, це захист планети від згубної сонячної радіації і один із регуляторів температури навколишнього середовища.

На сьогодні у світовій практиці існує достатньо велика кількість моделей, які достатньо адекватно описують процеси розсіювання шкідливих домішок в атмосферному повітрі. Закордонні розробки дають змогу провести розрахунок розсіювання забруднювальних речовин від промислових джерел (Prater \& Midgley, 2006; Beychok, 2005; Pal, 1998; Rod, 2001; Environmental Protection Agency, 1995).

Питання щодо атмосферного розсіювання вивчали такі вітчизняні та зарубіжні вчені: А. Н. Колмогоров, А. М. Обухов, М. Е. Берлянд, Д. Л. Лайхтман, Н. Л. Бизова, П. І. Андрєєв, І. Я. Сигал, В. М. Ельтерман, Г. І. Тейлор, В. Шмідт, О. Г. Сеттон, Ф. Пасквілл та ін.
(Steinzor, Subra \& Sumi, 2013; Brook \& Rajagopalan, 2010; Mykhailiuk, 2011; Wellenius, et al., 2012; Hovdiak \& Kosnyriev, 2007; Revazov \& Leonovich, 2014; Shestopalov, 2007; Gorniukova \& Galunova, 2014; Hovdiak, 2012; Varlamov, Pozniakov \& Yurashev, 2012).

На сьогодні накопичено матеріали про негативний вплив компресорних станцій (КС) на навколишнє середовище. КС викидають шкідливі речовини, які впливають на рослинний і тваринний світ, а також на приземний шар атмосфери. Найбільшу небезпеку створюють джерела забруднення атмосфери, пов'язані насамперед iз процесами спалювання неорганічного палива. У камерах згорання газоперекачувальних агрегатів газотурбінних двигунів утворюються такі шкідливі речовини, як: оксид і діоксид азоту, оксид вуглецю та ін., які забруднюють атмосферне повітря. Разом із тим процес спалювання газу є ще не достатньо регульованим, в атмосферу потрапляють токсичні продукти згорання газу, концентрація яких може перевищувати гранично допустимі рівні. Для газоперекачувальних агрегатів, що перебувають в експлуатації на КС, проблему зниження токсичності згорання газу ще не достатньо вирішено.

Отже, подальше вдосконалення технологій спалювання природного газу в камерах згорання, конструкцій газових пристроїв, методів прогнозування складу шкідливих викидів, які забруднюють атмосферу, та способів знешкодження шкідливих речовин $є$ актуальним і важливим технічним завданням, що потребує подальшого розвитку.

\section{Інформація про автора:}

Михайлюк Юлія Дмитрівна, канд. техн. наук, доцент кафедри екологіï. Email: umiha23@gmail.com

Цитування за Дсту: Михайлюк Ю. Д. Дослідження закономірностей розповсюдження викидів продуктів згорання в атмосферу під час роботи компресорних станцій. Науковий вісник НЛтУ України. 2018, т. 28, № 2. С. 133-136.

Citation APA: Mykhailiuk, Yu. D. (2018). Laws of Distribution of Compressor Stations Emissions of the Combustion Products in the Atmosphere. Scientific Bulletin of UNFU, 28(2), 133-136. https://doi.org/10.15421/40280225 
Матеріал і методи дослідження. Для вивчення явища розповсюдження викидів забруднювальних речовин, встановлення закономірностей їх поширення у приземному шарі, можна скористатися моделюванням руху газоповітряного потоку з урахуванням закономірностей, що пов'язують між собою характеристики газового викиду в атмосферу.

Розсіювання газових викидів відбувається завдяки турбулентній дифузії. В атмосфері окремі частинки, що викидаються, або групи частинок рухаються завдяки молекулярній i турбулентній дифузії. Одним iз найбільш істотних метрологічних чинників, що впливають на розповсюдження забруднювальних речовин, $\epsilon$ вітер.

Огляд вітчизняних літературних джерел показав, що проблеми моделювання розсіювання забруднювальних речовин в атмосферному повітрі залишаються достатньо актуальними для нашої країни. Враховуючи, що точність результатів розрахунку концентрацій токсичних домішок у випадку постійного чи аварійного викиду істотно впливає на правильність вибору, можливість застосування та ефективність використання необхідних природоохоронних заходів, спрямованих на зниження техногенного навантаження на навколишнє середовище та покращення екологічної ситуації в країні, необхідно в подальшій роботі розроблювати нові та вдосконалювати наявні методи моделювання процесів розповсюдження забруднень в атмосферному повітрі.

Атмосферна дифузія є складним і багатофакторним процесом. Розповсюдження домішок в атмосферному повітрі характеризуються двома видами дифузії: молекулярною, пов'язаною з випадковим і хаотичним рухом молекул, та турбулентною, зумовленою вихровим полем атмосфери. Під час роботи газоперекачувального агрегата на компресорній станції продукти згорання, що містять шкідливі речовини, такі як: оксиди азоту, діоксиди азоту, оксиди вуглецю та інші сполуки, можна мінімізувати, проте частина їх потрапляє в атмосферу.

Результати дослідження. На рис. зображено схему технологічного обладнання, що забезпечує викиди продуктів згорання в атмосферу. 3 газотурбінного двигуна викиди потрапляють до збірного колектора, з'єднаного 3 вертикальною викидною трубою висотою $h$ та діаметром $d$. Для дослідження руху частинок газу виберемо нерухому систему координат z0y, пов'язану з джерелом викидів. Вісь $z$ напрямимо по осі вертикальної труби, вісь $y$ - за напрямком вітру.

Під час руху димових газів у колекторі та димовій трубі відбувається їх змішування, яке залежить від діаметра і довжини колектора та викидної труби, режиму руху, властивостей газів, дифузії та ін.

Вважатимемо, що викидні гази, які надходять до колектора, змішуючись у викидній трубі, утворюють однорідну суміш, яка викидається із труби висотою $h$ зі швидкістю $V_{0}$, що визначається за формулою

$$
V_{0}=\frac{Q}{f},
$$

де: $Q$ - витрати викидного газу, $\mathrm{m}^{3} / \mathrm{c} ; f$ - площа поперечного перерізу труби.
Рух димових газів в атмосферному повітрі складається 3 переносного руху середовища та відносного руху викидних частинок - продуктів згорання. Під час руху газовикидної суміші відбуваються мікровзаємодії елементарних частинок у часі та просторі. У першому наближенні вважаємо, що центр виділеного об'єму рухається по криволінійній траєкторії, яка не змінюється від дифузійних процесів. На виділений об'єм викидного газу діють сила $G$ ваги і сила $F_{6}$ тиску вітру, які визначаються такими формулами:

$$
\begin{gathered}
G=m \cdot g, \\
F_{6}=k \cdot y^{\prime},
\end{gathered}
$$

де: $m$ - маса газу; $g$ - пришвидшення земного тяжіння; $k$ - коефіцієнт пропорційності; $y^{\prime}=v_{6}$ - швидкість вітру.

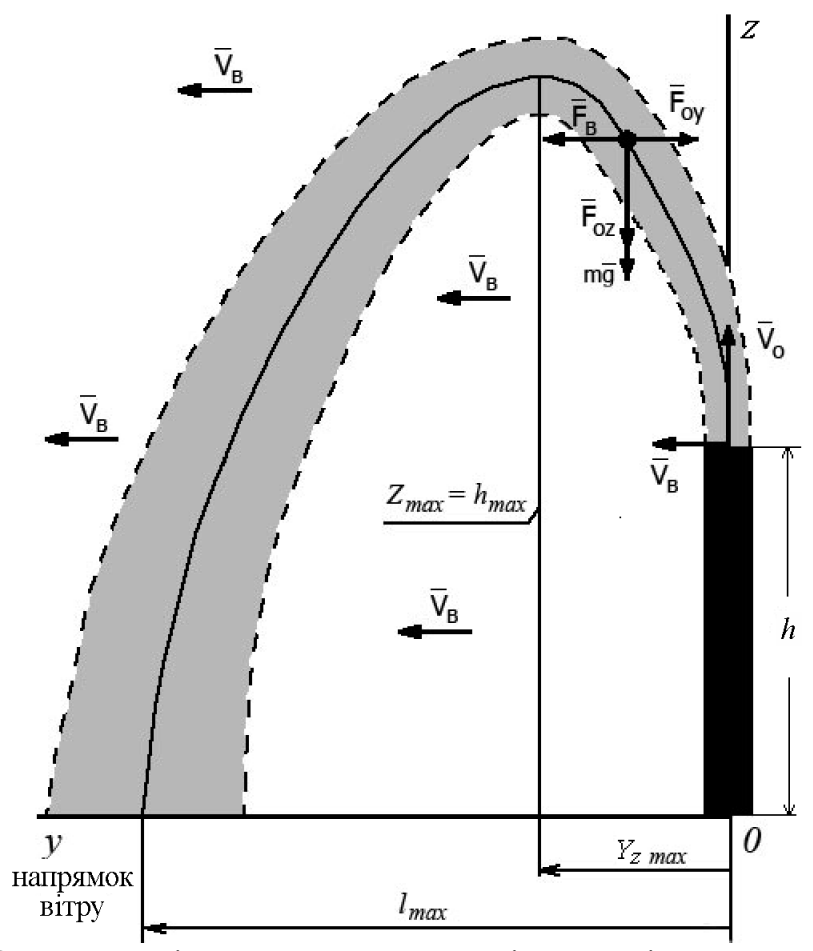

Рис. Траєкторія розповсюдження викидів продуктів згорання в атмосфері

Під час руху вверх сила $F_{o z}$ опору рухові напрямлена по осі $z$ у протилежний бік, а під час руху в горизонтальному напрямку - сила $F_{o y}$ паралельна до осі $y$ в бік, протилежний до руху.

$$
\begin{aligned}
& F_{o y}=K_{o y} \cdot y^{\prime}, \\
& F_{o z}=K_{o z} \cdot z^{\prime},
\end{aligned}
$$

де: $K_{o y}$ і $K_{o z}$ - коефіцієнти опору рухові в напрямках осей $y$ і $z ; y^{\prime}, z^{\prime}-$ проекції швидкостей центра виділеного об'єму на осі $y$ i $z$.

Напрямки зазначених сил показано на рис. Скориставшись принципом Даламбера, складемо диференціальні рівняння руху виділеного об'єму - розповсюдження речовин із викидної труби в проекціях на осі $y$ і $z$ у такому вигляді:

$$
\begin{aligned}
& m y^{\prime \prime}-\left(K+K_{o y}\right) \cdot y^{\prime}=0, \\
& m z^{\prime \prime}+K_{o z} \cdot z^{\prime}+m g=0 .
\end{aligned}
$$

Для розв'язування системи рівнянь (6) і (7) запишемо початкові умови, якщо

$$
t=0 ; y^{\prime}(0)=V_{b} ; y(0)=0 ; z^{\prime}(0)=V_{0} ; z(0)=h .
$$


Розв'язавши систему рівнянь (6) і (7), отримаємо закономірності руху центра виділеного об'єму в площині $y 0 z$ у такому вигляді:

$$
\begin{gathered}
y=\frac{V_{B} m}{K-K_{o y}} \cdot\left(\operatorname{Exp}\left(\frac{K-K_{o y}}{m} t\right)-1\right), \\
z=\frac{1}{K_{o z}^{2}}\left(h K_{o z}^{2}+\left(m^{2} g+m V_{o}\right)\left(1-\operatorname{Exp}\left(\frac{-K_{o z}}{m} t\right)\right)-m g K_{o z} t\right) .
\end{gathered}
$$

Залежності (9) і (10) описують рух центра виділеного об'єму в площині осей $y 0 z$. Якщо з цих залежностей вилучити параметр $t$, то отримаємо рівняння траєкторії руху центра виділеного об'єму у такому вигляді:

$$
\begin{gathered}
z=\frac{1}{K_{o z}^{2}}\left(h K_{z}^{2}+m\left(g m+V_{o}\right)\left(1-\operatorname{Exp}\left(\frac{-K_{o z} \cdot \Delta_{B}}{K-K_{o y}}\right)\right)-\frac{m^{2} g K_{o z}}{K-K_{o y}} \Delta_{B}\right), \\
\Delta_{B}=\ln \left|\frac{m V_{B}+y\left(K-K_{o y}\right)}{m V_{B}}\right| .
\end{gathered}
$$

Якщо задатися числовим значенням величин, що входять до залежності (11), то можна побудувати траєкторію руху викидних частинок.

Тривалість $T$ руху викидів із димової труби до приземлення можна визначити 3 рівняння (10) при $z=0$. Розв'язавши це рівняння, отримаємо значення

$$
T=f\left(h, V_{0}, m, g, K_{o z}\right) .
$$

Підставивши знайдене значення $T$ в рівняння (9) знайдемо дальність розповсюдження викидів, тобто:

$$
y_{\text {max }}=l_{\max }=\frac{V_{6} m}{K-K_{o y}}\left(e^{\frac{K-K_{o y}}{m} T}-1\right) .
$$

Залежність (13) дає змогу оцінити вплив швидкості $V_{0}$ викиду продуктів згорання, швидкості $V_{6}$ вітру, опору середовища $K, K_{o y}, K_{o z}$, висоти $h$ і діаметра викидної труби на дальність $l_{\max }$ розповсюдження продуктів згорання. Запропонований підхід допомагає також визначити максимальну висоту підйому продуктів згорання. Для цього необхідно прирівняти $z^{\prime}=0$, знайти час підйому частинок на максимальну висоту i, підставивши його в $(10)$, знайти $h_{\max }$.

Висновки. Ці залежності можна використати для якісної оцінки впливу характеристик середовища, вітрового навантаження і технологічних параметрів викиду, діаметра та висоти викидної труби і кількості викидних газів на перенесення викидних речовин у просторі. Запропоновані розрахункові залежності дають змогу оцінити зміну дальності розповсюдження шкідливих речовин залежно від швидкості викидних газів, висоти димової труби, напрямку і швидкості вітру та інших параметрів.

Відстань, на яку поширюються продукти згорання, пропорційна до швидкості вітру i функціонально пов'язана з масою та швидкістю викидів продуктів згорання, висотою викидної труби, коефіцієнтами опору середовища.

\section{Перелік використаних джерел}

Beychok, M. R. (2005). Fundamentals of Stack Gas Dispercion. California: Newport Beach.
Brook, R. D., \& Rajagopalan, S. (2010). Particulate matter air pollution and cardiovascular disease: An update to the scientific statement from the American Heart Association. Circulation, 121(21), 23312378. http://doi.org/10.1161/CIR.0b013e318

Environmental Protection Agency. (1995). User's Guide for the Industrial Source Complex (ISC3) Dispersion Models, 1(2), 123-129. Retrieved from: http://epa.gov/scram001/userg/regmod

Gorniukova, A. A., \& Galunova, D. V. (2014). Ekologicheskie problemy gazovoi promyshlennosti. Izvestiia Tulskogo GU. Seriia: Tekhnicheskie nauki, 11(2), 292-296. [in Russian].

Horbiichuk, M. I., \& Shchupak, I. V. (2011). Matematychni modeli prohnozuvannia vykydiv kompresornymy stantsiiamy shkidlyvykh rechovyn v atmosferu. Avtomatyka [Automatics], (pp. 84-85). Retrieved from: ena.ip.edu.ua. [in Ukrainian].

Hovdiak, R. M. (2012). Shliakhy pidvyshchennia enerhoekolohichnoi bezpeky ta efektyvnosti roboty mahistralnykh hazoprovodiv Ukrainy. Rozvidka ta rozrobka naftovykh $i$ hazovykh rodovyshch, 1(42). Retrieved from: http://nbuv.gov.ua/UJRN/rrngr. [in Ukrainian].

Hovdiak, R. M., \& Kosnyriev, Yu. M. (2007). Kilkisnyi analiz avariinoho ryzyku hazotransportnykh obiektiv pidvyshchenoi nebezpeky. Lviv: Kalvariia. 160 p. [in Ukrainian].

Hovdiak, R. M., \& Shymko, R. Ya. (2012). Znyzhennia shkidlyvoho vplyvu roboty kompresornykh stantsii. Truboprovidnyi transport, 3(75), 20-23. [in Ukrainian].

Khalatov, A. A., Kostenko, D. A., \& Parafiinyk, D. P. (2010). Rekonstruktsiia kompresornykh stantsii hazotransportnoi systemy Ukrainy z vykorystanniam hazoturbinnykh ta elektropryvidnykh hazoperekachuvalnykh ahrehativ. Naftova i hazova promyslovist, 1, 3032. [in Ukrainian].

Mikaelian, E. A. (2011). Otcenka nadezhnosti gazoturbinnogo oborudovaniia kompressornykh stantcii gazoprovodov. Promyshlennyi servis, 2, 28-35. [in Russian].

Mykhailiuk, Yu. D. (2011). Pobudova matematychnoi modeli prostorovo-chasovoho polia rozsiiuvannia $\mathrm{v}$ atmosferi dymovykh haziv fakelnykh ustanovok. Naftohazova enerhetyka: materialy Mizhnarodnoi naukovo-tekhnichnoi konferentsii, (pp. 37-43), 10-14 zhovtnia 2011 r., m. Ivano-Frankivsk. Ivano-Frankivsk: IFNTUNH. [in Ukrainian].

Pal, A. S. (1998). Air Pollution Meteorology and Dispersion. Oxford University Press.

Prater, E. T., \& Midgley, C. (2006). A new air dispersion modelling system is helping create more accurate industrial source models. Environmental Protection, 17(3), 416-431.

Revazov, A. M., \& Leonovich, I. A. (2014). Analiz avariinosti na kompressornykh stantciiakh magistralnykh gazoprovodov. Trudy RGU nefti i gaza imeni I. M. Gubkina, 2(275), 26-33. [in Russian].

Rod, B. (2001). Atmospheric Dispersion Modelling. Earthscan Publications.

Shestopalov, A. V. (2007). Povyshenie tochnosti kontrolia kontcentratcii vybrosov $\mathrm{v}$ atmosfere goroda statcionarnymi istochnikami. Abstract of Doctoral Dissertation for Technical Sciences (05.11.13 - Instruments and methods for monitoring the environment, substances, materials and products). Omsk. 20 p. [in Russian].

Steinzor, N., Subra, W., \& Sumi, L. (2013). Investigating Links between Shale Gas Development and Health Impacts through a Community Survey Project in Pennsylvania. New Solutions, 23(1), 5583. http://doi.org/10.2190/NS.23.1.e

Varlamov, H. B., Pozniakov, P. O., \& Yurashev, D. M. (2012). Kompleksni doslidzhennia enerhoekolohichnykh pokaznykiv ekspluatatsii HTU u skladi HPA typu HTK-10. Enerhosberezhenye, 1(95), 15-24. [in Ukrainian].

Wellenius, G. A., Burger, M. R., Coull, B. A., Schwartz, J., Sus, H. H., Koutrakis, P., Schlaug, G., Gold, D. R., \& Mittleman, M. A. (2012). Ambient Air Pollution and the Risk of Acute Ischemic Stroke. Archives of Internal Medicine, 172(3), 229-234. https://doi.org/10.1001/archinternmed.2011.732 


\section{ИССЛЕДОВАНИЕ ЗАКОНОМЕРНОСТЕЙ РАСПРОСТРАНЕНИЯ ВЫБРОСОВ ПРОДУКТОВ СЖИГАНИЯ В АТМОСФЕРУ ВО ВРЕМЯ РАБОТЫ КОМПРЕССОРНЫХ СТАНЦИЙ}

Рассмотрены основные загрязняющие вещества и их состав, которые чаще всего выбрасываются в атмосферу во время эксплуатации компрессорных станций магистральных газопроводов. Наибольшую опасность создают источники загрязнения атмосферы, связанные, в первую очередь, с процессами сжигания неорганического топлива. Установлено, что в камерах сгорания газоперекачивающих агрегатов газотурбинных двигателей образуются оксид и диоксид азота, оксид углерода и другие вещества, что загрязняют атмосферный воздух. Проведен анализ распространения выбросов загрязняющих веществ в атмосферном воздухе. Предложена схема траектории распространения выбросов продуктов сгорания в атмосфере. Разработаны математические зависимости загрязнения приземного слоя атмосферного воздуха выбросами дымовых газов от источников технологического оборудования во время работы компрессорных станций. Установлены закономерности распространения выбросов в приземном слое атмосферы. Предложены расчетные зависимости, которые позволят оценить изменение дальности распространения вредных веществ в зависимости от скорости выкидных газов, высоты дымовой трубы, направления и скорости ветра и других параметров. Охарактеризованы закономерности расстояния, на которое распространяются продукты сгорания, которое пропорционально скорости ветра и функционально связано с массой и скоростью выбросов продуктов сгорания, высотой выкидной трубы, коэффициентами сопротивления среды.

Ключевые слова: компрессорная станция; окружающая среда; продукты сжигания природного газа; атмосферный воздух.

Yu. D. Mykhailiuk

Ivano-Frankivsk National Technical University of Oil and Gas, Ivano-Frankivsk, Ukraine

\section{LAWS OF DISTRIBUTION OF COMPRESSOR STATIONS EMISSIONS OF THE COMBUSTION PRODUCTS IN THE ATMOSPHERE}

The authors have examined the development of scientific-technical methods and approaches to decreasing the detrimental effect of compressor stations emission into the atmospheric air. The current investigations of ecological safety level in the compressor stations location areas have been analysed. We have considered basic contaminants and their composition that are mostly thrown out in the atmosphere during exploitation of the compressor stations of main gas pipelines. The most danger is created by the sources of contamination atmospheres, constrained, first of all, with the processes of incineration of inorganic fuel. Oxide and dioxide of nitrogen, oxide of carbon and other, are defined to appear in combustion of gas compressor units of turbo-engines chambers, which contaminate atmospheric air. The analysis of distribution of extracts of contaminants in atmospheric air is conducted. The chart of trajectory of distribution of combustion products in the atmosphere is offered. Mathematical dependences of contamination of the ground layer of atmospheric air by flue gases emissions from the sources of technological equipment during the operation of the compressor stations are worked out. Conformities to the law of distribution of flue gases emissions in the ground layer of atmosphere are set. Calculation dependences, which will allow estimating the change of distance of distribution of harmful matters depending on speed of discharge gases, height of flue, direction and speed of wind and other parameters, are offered. The authors have described the regularities of the distance to which the combustion products are distributed, that is proportional to wind velocity and functionally related to mass and speed of flue gases emissions, in high discharge pipe, by the coefficients of resistance of environment. The obtained correlation has been applied at the study of discharged gases spreading considering the gases emission velocity, wind velocity and other characteristics.

Keywords: compressor station; environment; products of natural gas combustion; atmospheric air. 